\title{
Assessment of Prescribing Patterns and Health-Related Quality of Life in Cerebral Stroke Patients
}

\author{
Proveen Kothagundla ${ }^{1}{ }^{*}$, Kammili Radhika ${ }^{1}$, Kumar.V.S.Nemmani ${ }^{2}$, Mavulati Sri Chandana ${ }^{3}$ \\ 1. Pharm D Intern, Shri Vishnu College of Pharmacy, Bhimavaram, West Godavari District, Andhra Pradesh, India. \\ 2. Director (M.Pharm, PhD), Shri Vishnu College of Pharmacy, Bhimavaram, West Godavari District, Andhra Pradesh, India. \\ 3. Assistant professor (M.Pharm), Department of pharmacology, Shri Vishnu College of Pharmacy, Bhimavaram, West Godavari \\ District, Andhra Pradesh, India. \\ *Corresponding author's E-mail: proveen195@gmail.com
}

Received: 11-04-2021; Revised: 24-06-2021; Accepted: 30-06-2021; Published on: 15-07-2021. \begin{abstract}
Background and objectives: Stroke was one of the major public health challenges, not only for neuroscience but the society in general. This study aimed to assess the Prescribing Patterns and Health-Related Quality of Life in Cerebral Stroke patients. Methods: This is a prospective observational study for 6 months where patients diagnosed with cerebral stroke, satisfying the inclusion criteria were recruited and were categorized into Ischemic and hemorrhagic stroke. A standardised data collection was prepared and symptoms, risk factors and the prescription pattern of various drugs used were recorded. Quality of Life assessment was done by the Short Form36 questionnaire and paired t-test was used for determining any significance in the change detected before and after treatment. Results: Out of 150 patients' stroke was higher in males (63\%). The weakness of limbs (32\%) constitutes the major complaint. Major risk factors associated were hypertension (30\%), diabetes mellitus (18\%). Cognitive enhancers (16\%), antiplatelets (14\%) were the most prescribed class of drugs and in combination aspirin + clopidogrel was highly prescribed. The response score of all scales increased statistically ( $p$-value $<0.0001$ ) indicating improved Quality of life after treatment. Conclusion: Long term studies are further required to evaluate the benefit of combinational therapy over monotherapy and to develop standard guidelines for better management. Integration of the role of a pharmacist in the management of the disease is crucial and improves clinical outcomes of patients.
\end{abstract}

Keywords: Stroke, Symptoms, Risk factors, Prescribing pattern, Drugs, Quality of life

QUICK RESPONSE CODE $\rightarrow$

DOI:

10.47583/ijpsrr.2021.v69i01.030

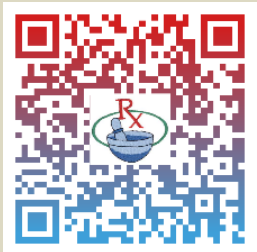

DOI link: http://dx.doi.org/10.47583/ijpsrr.2021.v69i01.030

\section{INTRODUCTION}

S

troke is a term used to describe an abrupt onset of focal neurologic deficit that lasts at least 24 hours and is assumed to be of vascular origin. Stroke can be either ischemic or hemorrhagic in origin. Transient ischemic attacks (TIAs) are focal ischemic neurologic deficits lasting less than 24 hours and are usually less than 30 minutes $^{1}$.

Types of Strokes include: - Ischemic stroke, Hemorrhagic stroke (SAH / ICH) and Transient Ischemic Attack (TIA)..$^{2-6}$

The estimated adjusted prevalence rate of stroke range in rural and urban areas was 84-262 / 100,000 and 334-424 / 100,000 , respectively and the incidence rate is $119-145$ / 100 , according to stroke factsheet $2012^{7,8,9}$. The third commonest cause of death worldwide after coronary heart disease (CHD) and cancer of all types was a stroke $e^{10,11,12}$. The mortality rate due to stroke in India was 22 times that of malaria and 1.4 times that of tuberculosis. Risk factors can be modifiable and non-modifiable. Smoking, alcoholism, atrial fibrillation, hyperlipidemia, hypertension, physical inactivity, obesity and postmenopausal hormone therapy constitutes modifiable risk factors whereas non-modifiable risk factors include old age, males and family history of stroke, race (African American, Asian, Hispanic). High blood pressure and diabetes are common risk factors among Indians $s^{13,1,4,7,8}$.

Nowadays, the diagnosis of stroke is done by FAST examination which includes weakness of the face, arm, speech disturbance and essentially time. CT scan, MRI scan, PET and ultrasound were the other means of diagnosis ${ }^{14,3,10}$. Symptoms and physical findings most often include sudden onset of facial weakness, arm drift, and abnormal speech, severe headache ${ }^{15}$.

For acute thrombotic stroke, proven treatments include IV thrombolysis within 3 hours of the onset of symptoms, use of aspirin within 48hours and decompressive surgery for malignant middle cerebral artery infarction ${ }^{3}$. Stroke can cause myriad of negative consequences on an individual's life ranging from institutionalization, loss of independence to cognitive and communication difficulties ${ }^{16}$. Stroke in young causes economic, social burdens on families and society and also deteriorates the quality of life of a person by its functional limitations ${ }^{17,2}$. The greater the morbidity and disability, the lesser the quality of life of stroke survivors ${ }^{18}$ 
Pharmacists are in a key role to provide pharmaceutical care to stroke survivors, review patients profile for risk factors, whenever necessary either to recommend or initiate appropriate drug therapy if indicated. To improve patient outcomes, integrating the pharmacist in the management of stroke patients and also educating them plays a vital role 4 .

It would be better to review stroke preventive ways, as there will be a rapid increase in the burden of stroke in the coming years and restricted accessibility of stroke care in India. The present study aims to provide a broad review of gender differences, demographics, risk factors, symptoms, prescribing pattern and Health-Related Quality of Life (HRQoL) of cerebral stroke patients.

\section{MATERIALS AND METHODS}

\section{Study site and design}

A prospective observational study was carried out over hospitalized cerebral stroke patients from July to December 2019 at Sivaranjani super speciality hospital. It is a tertiary care hospital specialized in neurology department which treats the patients in Bhimavaram town and nearby areas regarding various neurological disorders. Every day 100 to 150 patients were treated either in inpatient (IPD) or outpatient department (OPD).

\section{Study criteria}

\section{Inclusion criteria}

- Male and female patients of age $\geq 20$ years

- Patients who are diagnosed with cerebral stroke (Ischemic, Hemorrhagic and TIA)

- Patients who are willing to give consent form to participate in the study

\section{Exclusion criteria}

- $\quad$ Children, Pregnant women, patients who are having a seriously debilitating condition like End-stage renal disease, HIV, Cancer

- Patients with disabilities before the incident of stroke due to various other diseases

\section{Study procedure}

\section{Data collection}

An approval of ethical clearance has been obtained from the Institutional Ethical Committee before the initiation of the study. Subjects who met the inclusion criteria (150) were enrolled for the study. Details regarding the sociodemographics, past medical and medication history and current medications were obtained by patient or care giver interview and by observing case notes and captured in valid data collection form, patient's health-related quality of life information was measured by using SF-36 questionnaire.

\section{Data Analysis / Statistics}

Descriptive statistics of demographic and clinical variables included percentages, mean and standard error of the mean (S.E.M). Mean scores before and after treatment and mean changes were calculated for the domains of SF36. A paired t-test was used to determine if the change detected from the before and after treatment was significant. The probability value of $\leq 0.05$ was set as significant and $\leq 0.001$ as highly significant. All statistical analysis was performed using Graph Pad Prism version 8.3.0 (San Diego, California, USA).

\section{Ethical consideration}

The study was carried out from July 2019 to December 2019 after due permission from the Institutional Ethics Committee (Ref No: SVCP/IEC/16/12; dated: 29/07/2019) and after getting consent (in written form) from all the participating subjects.

\section{RESULTS}

Demographics: Table 1: Demographical characteristics of participants

\begin{tabular}{|c|c|c|c|c|}
\hline Category & Type & No. of patients & Percentage (\%) & Mean \pm S.E.M \\
\hline \multirow{3}{*}{ Gender } & Male & 109 & 63 & $60 \pm 1$ \\
\hline & Female & 41 & 37 & $60 \pm 2$ \\
\hline & Total & 150 & 100 & $60 \pm 1$ \\
\hline \multirow{7}{*}{ Age group } & $21-30$ & 4 & 2 & - \\
\hline & $31-40$ & 6 & 4 & - \\
\hline & $41-50$ & 25 & 17 & - \\
\hline & $51-60$ & 46 & 31 & - \\
\hline & $61-70$ & 40 & 27 & - \\
\hline & $71-80$ & 24 & 16 & - \\
\hline & $>80$ & 5 & 3 & - \\
\hline \multirow{3}{*}{ Type of Stroke } & Ischemic & 132 & 88 & - \\
\hline & Hemorrhagic & 12 & 8 & - \\
\hline & TIA & 6 & 4 & - \\
\hline
\end{tabular}


A total of 150 patients was enrolled in our study. 63\% were males and $37 \%$ were females. Patients ageing $\geq 20$ years were enrolled and among them most of the patients were in the age group of $51-60(31 \%)$, followed by $61-70(27 \%)$, $41-50(17 \%), 71-80(16 \%)$ and least were noted in the age group of $21-30(2 \%)$ with a mean age group of $60 \pm 1$ (Mean \pm S.E.M) (Table 1).

\section{Risk factor}

This study revealed that, out of 150 patients the risk factor of hypertension is about $30 \%$, diabetes mellitus is about $18 \%$ followed by alcohol $16 \%$, smoking $13 \%$, history of stroke (old CVA) $10 \%$, obesity $5 \%$, hyperlipidemia $3 \%$, head injury $2 \%, C A D 2 \%$ and seizures $1 \%$. Hypertension and diabetes mellitus were the most common risk factors for the cause of cerebral stroke (Figure 1).

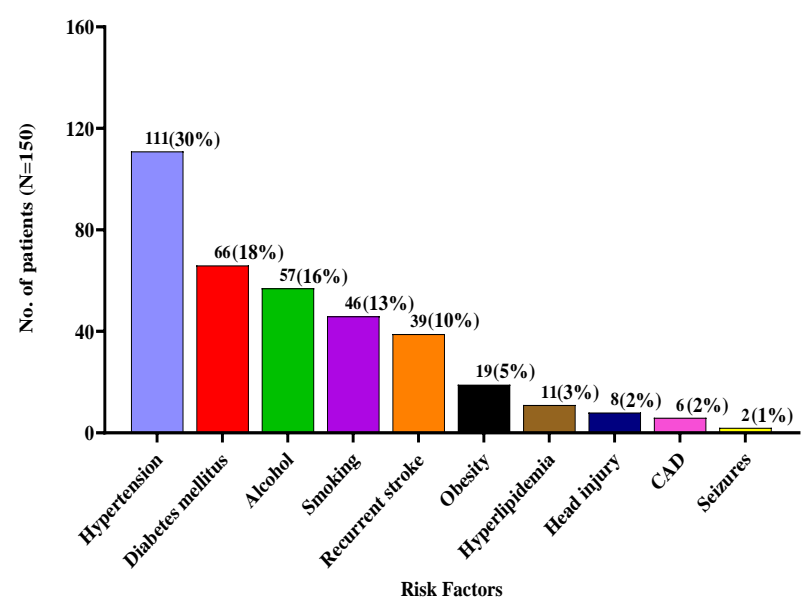

Figure-1: Distribution of study population based on risk factors

\section{Presenting complaints}

Majority of patients reported to have weakness of limbs $(32 \%)$, slurred speech (15\%), hemiparesis (7\%), giddiness $(6 \%)$, difficulty walking (6\%), other minor complaints such as headache $(5 \%)$, hemiplegia $(5 \%)$, deviation of mouth (5\%), tingling sensation (5\%), altered sensorium (5\%), and miscellaneous (9\%) including pain (4\%), blurred vision (2\%), facial palsy (2\%), tremors (1\%) (Figure 2 ).

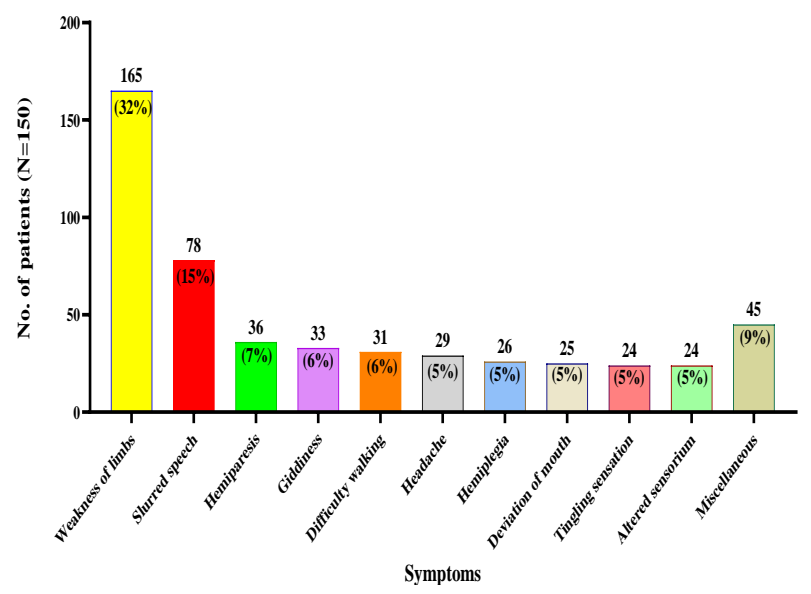

Figure-2: Prominent presenting complaints in study population

\section{Medications}

Table 2: Distribution of medications prescribed to the patients

\begin{tabular}{|c|c|c|}
\hline S.no & Class of drugs & Percentage (\%) \\
\hline 1 & Cognitive Enhancers & 16 \\
\hline 2 & Antiplatelets & 14 \\
\hline 3 & PPIS & 14 \\
\hline 4 & Dyslipidemics & 12 \\
\hline 5 & Antihypertensives & 12 \\
\hline 6 & Anticoagulants & 8 \\
\hline 7 & Analgesics & 7 \\
\hline 8 & Antidiabetics & 7 \\
\hline 9 & Multivitamins & 3 \\
\hline 10 & Antiepileptics & 3 \\
\hline 11 & Antidepressants & 2 \\
\hline 12 & Antibiotics & 2 \\
\hline
\end{tabular}

Study results revealed that cognitive enhancers (16\%) as supportive therapy are most commonly present in every prescription followed by antiplatelets (14\%), PPIs (14\%), dyslipidemics (12\%), antihypertensives (12\%), anticoagulants (8\%), analgesics (7\%), antidiabetics (7\%), antiepileptics (3\%), antidepressants (2\%) and antibiotics (2\%).

Table 3: Core monotherapy prescribed

\begin{tabular}{|c|c|c|}
\hline S. No & Drugs & Percentage (\%) \\
\hline 1 & Atorvastatin & 43 \\
\hline 2 & Enoxaparin Sodium & 31 \\
\hline 3 & Clopidogrel & 10 \\
\hline 4 & Amlodipine & 7 \\
\hline 5 & Mannitol & 4 \\
\hline 6 & Rosuvastatin & 3 \\
\hline 7 & Aspirin & 2 \\
\hline
\end{tabular}

Mostly used core single drug was atorvastatin (43\%) followed by enoxaparin sodium (31\%), clopidogrel (10\%) and least prescribed was aspirin (2\%).

Table 4: Core combination therapy prescribed

\begin{tabular}{|c|c|c|}
\hline S.no & Drugs & Percentage (\%) \\
\hline 1 & Aspirin + Clopidogrel & 86 \\
\hline 2 & Antiplatelet + Statin & 14 \\
\hline
\end{tabular}

Majorly prescribed combination drug was aspirin + clopidogrel $(86 \%)$ and least prescribed was atorvastatin + aspirin, atorvastatin + clopidogrel, rosuvastatin + clopidogrel constituting antiplatelet + statin (14\%) (Table 4). 


\section{Health related quality of life}

Table 5: Comparison of mean scores of SF-36 scales before and after treatment

\begin{tabular}{|c|c|c|c|c|}
\hline SF-36 scale (Q. No) & Treatment & $\mathbf{N}$ & Mean \pm S.E.M & $P$ value \\
\hline \multirow{2}{*}{ Physical functioning (Q: 3-12) } & Before & 150 & $56.4 \pm 6.0$ & \multirow{2}{*}{$\begin{array}{c}0.0001 \\
(\mathrm{HS})\end{array}$} \\
\hline & After & 150 & $78.9 \pm 5.0$ & \\
\hline \multirow{2}{*}{ Role limitation due to physical health (Q: 13-16) } & Before & 150 & $28.2 \pm 1.0$ & \multirow{2}{*}{$\begin{array}{c}0.0001 \\
(\mathrm{HS})\end{array}$} \\
\hline & After & 150 & $82.0 \pm 0.9$ & \\
\hline \multirow{2}{*}{$\begin{array}{l}\text { Role limitation due to emotional problems (Q: } \\
\qquad 17-19)\end{array}$} & Before & 150 & $38.4 \pm 0.6$ & \multirow{2}{*}{$\begin{array}{c}0.0001 \\
(\mathrm{HS})\end{array}$} \\
\hline & After & 150 & $73.3 \pm 0.4$ & \\
\hline \multirow{2}{*}{ Energy/Fatigue $(Q: 23,27,29,31)$} & Before & 150 & $56.8 \pm 9.0$ & \multirow{2}{*}{$\begin{array}{c}0.0001 \\
(\mathrm{HS})\end{array}$} \\
\hline & After & 150 & $73.9 \pm 6.0$ & \\
\hline \multirow{2}{*}{ Emotional wellbeing (Q: $34,25,26,28,30)$} & Before & 150 & $62.6 \pm 8.0$ & \multirow{2}{*}{$\begin{array}{c}0.0001 \\
(\mathrm{HS})\end{array}$} \\
\hline & After & 150 & $79.2 \pm 6.0$ & \\
\hline \multirow{2}{*}{ Social functioning (Q:20,32) } & Before & 150 & $54.1 \pm 2.0$ & \multirow{2}{*}{$\begin{array}{c}0.0001 \\
(\mathrm{HS})\end{array}$} \\
\hline & After & 150 & $79.4 \pm 0.3$ & \\
\hline \multirow{2}{*}{ Pain (Q:21,22) } & Before & 150 & $62.9 \pm 0.6$ & \multirow{2}{*}{$\begin{array}{c}0.0001 \\
(\mathrm{HS})\end{array}$} \\
\hline & After & 150 & $85.4 \pm 2.0$ & \\
\hline \multirow{2}{*}{ General health (Q:1, 33-36) } & Before & 150 & $51.7 \pm 9.0$ & \multirow{2}{*}{$\begin{array}{c}0.0001 \\
(\mathrm{HS})\end{array}$} \\
\hline & After & 150 & $70.1 \pm 5.0$ & \\
\hline \multirow{2}{*}{ Health change (Q: 2) } & Before & 150 & $29.9 \pm 0.0$ & \multirow{2}{*}{$\begin{array}{c}0.0001 \\
(\mathrm{HS})\end{array}$} \\
\hline & After & 150 & $70.7 \pm 0.0$ & \\
\hline
\end{tabular}

HS: Highly-significant.

The mean value of physical functioning before treatment is 56.4 and after treatment is 78.9. The difference in means is highly statistically significant $(P<0.0001)$. The mean role limitation due to physical health pre-treatment is 45.7 and post-treatment was 82.0 . The difference in means is highly statistically significant $(\mathrm{P}<0.0001)$. The mean role limitation due to emotional problem pre-treatment is 43.6 and post-treatment is 73.3. The difference in means is highly statistically significant $(P=0.0001)$. The mean energy/ fatigue pre-treatment is 56.8 and post-treatment are 73.9. The difference in means is highly statistically significant $(\mathrm{P}=0.0001)$. The mean Emotional wellbeing pretreatment is 62.6 and post-treatment is 79.2. The difference in means is highly statistically significant $(P=0.0001)$. The mean social functioning pre-treatment is 54.1 and post-treatment is 79.4. The difference in means is highly statistically significant $(P=0.0001)$. The mean pain score pre-treatment is 62.9 and post-treatment is 85.4. The difference in means is highly statistically significant $(P=0.0001)$. The mean general health score pre-treatment is 51.7 and post-treatment is 70.1. The difference in means is highly statistically significant $(P=0.0001)$. The mean health change pre-treatment is $\mathbf{4 7 . 7}$ and post-treatment is 70.7. The difference in means is highly statistically significant $(P=0.0001)$. The response score of all scales increased significantly ( $p<0.0001$ ), which indicates the improvement in Quality of life of stroke survivors after treatment (Table 5).
Table 6: Mono Vs Multiple therapy health score change

\begin{tabular}{|c|c|c|}
\hline Domain & Monotherapy & Combination \\
\hline $\begin{array}{c}\text { Physical functioning } \\
\text { (Q: 3-12) }\end{array}$ & 24.7 & 18.5 \\
\hline $\begin{array}{c}\text { Role limitation due } \\
\text { to physical health } \\
\text { (Q: 13-16) }\end{array}$ & 55.9 & 53.0 \\
\hline $\begin{array}{c}\text { Role limitation due } \\
\text { to emotional } \\
\text { problems (Q: 17-19) }\end{array}$ & 17.2 & 39.8 \\
\hline $\begin{array}{c}\text { Energy/Fatigue } \\
\text { (Q:23,27,29,31) }\end{array}$ & 16.6 & 18.7 \\
\hline $\begin{array}{c}\text { Emotional well } \\
\text { being (Q: 34, 25, 26, } \\
\text { 28, 30) }\end{array}$ & 14.5 & 27.4 \\
\hline $\begin{array}{c}\text { Social functioning } \\
\text { (Q:20,32) }\end{array}$ & 21.5 & 26.8 \\
\hline $\begin{array}{c}\text { Pain (Q:21,22) } \\
\text { General health (Q:1, } \\
\text { 33-36) }\end{array}$ & 19.7 & 23.6 \\
\hline \begin{tabular}{c} 
Health change (Q: 2$)$ \\
\hline
\end{tabular} & 35.7 & 42.7 \\
\hline
\end{tabular}

Multiple therapies using patients have an improvement in the quality of life in all domains compared to monotherapy 
patients except in the domains of physical functioning and role limitation due to physical health where monotherapy using patients have shown best results than combination therapy (Table 6).

\section{DISCUSSION}

The present study is done to assess the symptoms, risk factors, prescribing pattern of drugs and to evaluate their impact on the quality of life of cerebral stroke patients admitted in a tertiary care hospital, Bhimavaram.

The total number of patients enrolled under this study group were $N=150$, the distribution of males $(63 \%)$ is greater than females (37\%). The observation is in agreement with the findings of the study conducted by Jithin kc et al (2016) and Mathew E et al (2017) where males are affected more than females. Which can be attributed due to a) Estradiol has potent effects on endothelia that promote dilation of blood vessels and blood flow, whereas testosterone has opposite effects. This indicates women are protected by endogenous estrogens b) Males are more prone to HTN and DM than females c) Smoking ${ }^{12,19}$.

The data from this study shows that major type stroke observed in our patients was Ischemic (88\%) followed by Hemorrhagic (8\%) and TIA (4\%) which was in accordance with study by Prathyusha B et al (2014) and Vurumadla S et al $(2015)^{4,13}$.

Most patients in our study presented with complaints of weakness of limbs (32\%), slurred speech (15\%), hemiparesis $(7 \%)$, giddiness $(6 \%)$, difficulty walking $(6 \%)$ etc., Similarly, in the study by Dc RAL et al (2010) in Mississippi chiropractic practice patients presented with complaints of unilateral arm weakness and slurred speech, other complaints included episodic loss of vision, dysphagia, dysphonia, and same-sided leg weakness ${ }^{15}$. Contrastingly the study results of Vurumadla $S$ et al (2015) showed that symptoms like slurred speech, followed by weakness on the right side in 97 (65\%) patients, headache in $88(59 \%)$ patients, change in a speech in $87(58 \%)$ patients, weakness on the left side in 58 (39\%) patients and deviation of mouth in 48 (32\%) patients ${ }^{13}$.

The data of our study regarding risk factors of cerebral stroke in our patients showed that hypertension (30\%) is the major cause followed diabetes mellitus (18\%), alcohol $(16 \%)$ and smoking (13\%). A study conducted by Vurumadla $S$ et al (2015) shows similar results where the most common risk factors associated with the stroke was hypertension in 102 (68\%) patients, followed by dyslipidemia in 81 (54\%) patients, diabetes mellitus in 51 (35\%) patients and heart disease in 49 (33\%) patients ${ }^{13}$.

A thorough screening was made into all the prescriptions of our study participants where cognitive enhancers (16\%) as supportive therapy are mostly present in every prescription followed by antiplatelets (14\%), PPIs (14\%), dyslipidemic agents (12\%), antihypertensives (12\%), anticoagulants $(8 \%)$, analgesics $(7 \%)$ for pain and antidiabetics (7\%) for patients with elevated blood sugar levels, for post-stroke seizures and depression drugs such as antiepileptics and antidepressants were given respectively, for hospital born infection prophylaxis antibiotics (2\%) were given, similar results were obtained in the study of Jithin kc et al (2016) where the patients are prescribed with antiplatelets, anticoagulant, antihypertensive, statins, and antidiabetics, antidepressants, antiepileptics, multivitamins, and laxatives, GI protectants ${ }^{19}$.

A study conducted by Konduru SST et al (2017) shows that the most frequently used drugs were antiplatelet (clopidogrel) - 70 (21\%), psychostimulant (citicoline) - 67 (20\%) and dyslipidemic (atorvastatin) - 56 (16\%). Similarly, in our study mostly used core single drug was atorvastatin (43\%) followed by enoxaparin sodium (31\%), clopidogrel $(10 \%)$ and least prescribed was Aspirin $(2 \%)^{22}$.

Our study results show that majorly prescribed combination drug was aspirin + clopidogrel $(86 \%)$ and least prescribed was atorvastatin + aspirin, atorvastatin + clopidogrel, rosuvastatin + clopidogrel combining $14 \%$. A study conducted by Konduru SST et al (2017) shows aspirin + clopidogrel was the major prescribed combination therapy in stroke patients which favours our study ${ }^{22}$.

A study by Rajan B et al (2019) said that QoL showed significant improvements in all physical, psychological and social domains by the end of the 6th month of followup, the results were similar with our study where response score of all scales increased significantly $(p<0.0001)$, which indicates the improvement in Quality of life of stroke survivors after treatment ${ }^{9}$. Whereas Mahran S et al (2015) study says that low mean scores of all the nine domains of SF-36 were found which is opposite to our study result. This may be due to poor adherence of patients regarding their medications and lifestyle modifications designed by their physicians, stringent implementation of awareness and counselling regarding the effectiveness of treatment should be implemented ${ }^{21}$.

Patients taking mono and combination therapy are assessed for their health score before and after therapy and the change in score was noted and compared. Multiple therapies using patients have an improvement in the quality of life in all domains compared to monotherapy patients except in the domains of physical functioning and role limitation due to physical health where monotherapy using patients have shown best results than combination therapy. Although clopidogrel-aspirin therapy seems to have substantially reduced the risk of stroke in the patients in comparison with aspirin-alone therapy, there is still a large proportion of patients at high risk of stroke despite clopidogrel treatment. Wang $Y$ et al (2015) study shows that there was a slight benefit in patients taking combined therapy compared with monotherapy which is similar to the findings in our study ${ }^{20}$. 


\section{CONCLUSION}

Cerebral stroke is a multi-factorial health problem, and its prevalence and risk factors have changed considerably within the past century. The study finds the higher prevalence of cerebral stroke among males and in the age group of 51-60 years with major risk factors constituting hypertension, DM. The weakness of limbs, slurred speech and hemiparesis were the most commonly reported symptoms. Antiplatelets (clopidogrel), dyslipidemic agent (atorvastatin) and anticoagulants (enoxaparin sodium) were mostly prescribed single drugs along with cognitive enhancers and gastro protectives; in multiple therapy aspirin + clopidogrel constitutes major proportion. There was a statistical improvement in the health-related quality of life in cerebral stroke patients by the course of treatment and self-care. Prevalent cerebrovascular risk factors (hypertension, DM) increased the risk of getting a stroke, thereby identifying and managing them priorly with rational use of treatment decreases the worsening of the disease and co-morbidities. Long term studies are further required to evaluate the benefit of combinational therapy over monotherapy and to develop standard guidelines for better management. Integration of the role of a pharmacist in the management of the disease is crucial and improves clinical outcomes of patients.

Acknowledgement: We thank Dr. Ch. Sivaranjani. MD., D.M. (NIMS) Consultant Neurologist and staff of Sivaranjani Super Speciality Hospital for providing all facilities required to undertake the study. We also thank Dr. K. Prasad, M.Pharm, PhD, Principal, Shri Vishnu College of Pharmacy, Bhimavaram, for their cordial support.

\section{REFERENCES}

1. Wells BG, Dipiro JT, Dipiro CV, Schwinghammer TL. Pharmacotherapy Handbook. 2009; Vol. 7: 31- 42.

2. Sangam S, Naveed A, Athar M, Prathyusha P, Moulika S, Lakshmi S. A Study on Functional Measures in Patients with Stroke. International Journal of Health Sciences and Research (IJHSR). 2015; 5(1): 156-64.

3. Swetha K, Singh S. A retrospective study of prescription pattern of drugs in the management of stroke, at BRIMS teaching hospital, Bidar, India. Int J Basic Clin Pharmacol. 2018 Oct; 7: 1929-33. doi: https://dx.doi.org/10.18203/2319-2003.ijbcp20183925

4. Preethi PB, Naveed A, Shreya S, Lakshmi SG, Rao V. Prescribing pattern of drugs in stroke patients admitted to a multi-specialty hospital, India. Indo Am J Pharm Res. 2014; 4(2): 1015-20.

5. Håheim LL, Holme I, Hjermann I, Tonstad S. Risk-factor profile for the incidence of subarachnoid and intracerebral haemorrhage, cerebral infarction, and unspecified stroke during 21 years' follow-up in men. Scandinavian journal of public health. 2006 Dec; 34(6): 589-97.doi: 10.1080/14034940600731523. PMID: 17132592.

6. Feigin VL, Wiebers DO, Nikitin YP, O'Fallon WM, Whisnant JP. Risk factors for ischemic stroke in a Russian community: a population-based case-control study. Stroke. 1998 Jan; 29(1): 34-9. doi: 10.1161/01.str.29.1.34. PMID: 9445325.

7. Abbasi MY, Ali MA. Prescribing pattern of drugs in stroke patients: A prospective study. Arch Pharma Practice. 2012 Oct 1; 3(4): 283. doi: 10.4103/2045-080X.106253

8. Pandian JD, Sudhan P. Stroke epidemiology and stroke care services in India. J Stroke. 2013 Sep;15(3):128-34. doi: 10.5853/jos.2013.15.3.128. Epub 2013 Sep 27. PMID: 24396806;

9. Rajan B, Pruthvish S, Lalitha K, Tyloth M, Murthy NS. Assessment of quality of life among stroke survivors: a longitudinal study. Int J Community Med Public Health. 2019; 6(3): 1316-23.doi: http://dx.doi.org/10.18203/23946040.ijcmph20190633

10. Ansari AK, AKHUND IA, SHAIKH AQ. Stroke in elderly; identification of risk factors. Journal of Ayub Medical College Abbottabad. 2001; 13(3): 11-3.

11. Almborg A, Ulander K, Thulin A, Berg S. Discharged after stroke - important factors for health-related quality of life.Journal of Clinical Nursing. 2010; 2196-206. doi: 10.1111/j.1365-2702.2010.03251

12. Mathew E, C. C, Karanath PM, R. S. a Prospective Observational Study on Prescribing Trends and Adverse Drug Reactions in Stroke Patients. Int J Pharm Pharm Sci. 2017; 9(7): 25-30. doi https://doi.org/10.22159/ijpps.2017v9i7.14189

13. Vurumadla S, Rakshith V, Murari $\mathrm{CH}$, Venkateshwarlu K. A study on symptoms, risk factors and prescribing pattern of drugs used in stroke patients. Int J Pharm Pharm Sci. 2015; 7(1): 421-6.

14. Naess $H$, Waje-Andreassen $U$, Thomassen $L$, Nyland $H$, Myhr KM. Health-related quality of life among young adults with ischemic stroke on long-term follow-up. Stroke. 2006 May 1; 37(5): 1232-6.DOI: 10.1161/01.STR.0000217.652.42273.02

15. Leach RA. Patients with symptoms and signs of stroke presenting to a rural chiropractic practice. Journal of manipulative and physiological therapeutics. 2010 Jan 1; 33(1): 62-9. Doi: 10.1016/j.jmpt.2009.11.004

16. Kulina $D$, Chomicka A, Fidecki W, Wysokiński $M$, Chruściel $\mathrm{P}$, Zdanowicz T. Assessment of the Quality of Life in Patients Recovering after a Cerebral Stroke. The Journal of Neurological and Neurosurgical Nursing. 2017; 6(4): 163-9. DOI: 10.15225/PNN.2017.6.4.5

17. Rolfs A, Fazekas F, Grittner $U$, Dichgans $M$, Martus $P$, Holzhausen M, Böttcher T, Heuschmann PU, Tatlisumak T, Tanislav C, Jungehulsing GJ. Acute cerebrovascular disease in the young: the Stroke in Young Fabry Patients study. Stroke. 2013; 44(2): 340-9. DOI: 10.1161/STROKEAHA.112.663708

18. Mudaliar MR, Yiragamreddy SR, Tejashwani PP, Umapathi $S$, Sake N, Sharma S. Quality of Life in Stroke Patients Using SSQoL Scale and Barthel Index. Indian Journal of Pharmacy Practice. 2018; 11(1): $44-50$. 
DOI: 10.5530/ijopp.11.1.8

19. Jithin KC, Arya G, Lekshmi P, Lakshmi R. A study on the pattern of prescribing medications used in secondary prevention of stroke. Asian J Pharm Clin Res.2016; 9(3): 328-30.

DOI:

http://dx.doi.org/10.22159/ajpcr.2016.v9s3.14071.

20. Wang $Y$, Pan $Y$, Zhao $X$, Li H, Wang D, Johnston SC, Liu L, Meng X, Wang A, Wang C, Wang Y. Clopidogrel with aspirin in acute minor stroke or transient ischemic attack (CHANCE) trial: one-year outcomes. Circulation. $2015 \mathrm{Jul}$ 7;
132(1): 40-6. DOI: 10.1161/CIRCULATIONAHA.114.014791.

21. Mahran S, Abdulrahman M, Janbi F, Jamalellail R. The health-related quality of life in stroke survivors: clinical, functional, and psychosocial correlate. Egypt Rheumatol Rehabil.2015; 42(4): 188-95. DOI: 10.4103/1110161X.168198.

22. Konduru SST, Ranjan A, Nallajerla JS, Gonuguntala S. Study of Symptoms, Risk Factors and Prescribing Patterns in Cerebral Stroke Patients. Indian Journal of Pharmacy Practice.2017; 10(1): 20-6. DOI: 10.5530ijopp.10.1.6.

Source of Support: The author(s) received no financial support for the research, authorship, and/or publication of this article.

Conflict of Interest: The author(s) declared no potential conflicts of interest with respect to the research, authorship, and/or publication of this article.

For any question relates to this article, please reach us at: editor@globalresearchonline.net

New manuscripts for publication can be submitted at: submit@globalresearchonline.net and submit_ijpsrr@rediffmail.com 